\title{
State of the art of technology in the Food sector value chain towards the IoT
}

\author{
Lucia Ramundo, Marco Taisch and Sergio Terzi
}

\begin{abstract}
The food sector is challenged to provide safe and qualitative food to consumers at affordable price and to feed appropriately increasing population using natural resources, like soil and water, in a sustainable way. Consumers awareness about food origin, nutritional and wellness properties, attention to processed meals ingredients, due to health issues, and requests of new customized portions formats and receipts, related to habits changes, are also demanding trends in the sector. Several technologies can help to address those responsibilities of efficient, safe and environmental respectful production, and strict communication and connection with the consumers. This paper provides a state of the art of smart and other emerging technologies framed in the whole food supply-chain, to create a picture of the added value that the technology can bring to the sector. Moreover, the evolutions towards the Internet of Things (IoT) paradigm adoption are presented.
\end{abstract}

Index Terms - food sector; smart technologies; IoT; virtualization; smart farming; precision agriculture; additive manufacturing; 3D printing; traceability; supply-chain integration; smart packaging; food safety

\section{INTRODUCTION}

$\mathrm{W}$ HILE several studies have been conducted on usage of technology in the food sector, there is still the need to frame it in the whole value chain and towards the Internet of Things perspective. This paper resumes the main available and applied technologies along the food supply-chain, in order to create a picture of the added value that the technology brings to the sector and future benefits related to IoT paradigm adoption. This is relevant to understand the main developments in the different areas of the supply chain, to evaluate current and possible new connections along the supply-chain and among different technologies and to stimulate regulations gaps, needed changes and updates in the food and technology legislation. The paper also provides an overview, with examples, of new technologies usage at commercial level, which can have future impact on the food business. Since the research has been focused mainly on the Italian market, the reported use cases of technology adoption from research and market are overall related to the Italian situation.

Submitted on $10^{\text {th }}$ June 2016

Lucia Ramundo, Marco Taisch, Sergio Terzi are with

Department of Management, Economics and Industrial Engineering

Politecnico di Milano, via Lambruschini 4/B, 20156 Milan, Italy

(e-mail: lucia.ramundo@polimi.it,_marco.taisch@polimi.it,

sergio.terzi@polimi.it)

\section{METHODS}

This paper is based on scientific literature review, European Community funded project results, market researches, conferences speeches during commercial fairs and specialized press articles, in order to consider not just the research outputs, but also the commercial trends driven by technology diffusion. The research has been conducted with an empirical and qualitative method as a baseline to better understand the food sector in term of technological exposure. Starting point has been the investigation of ICT and IoT solutions, since smart connected objects are changing the landscape of several businesses. During such exploration, some other technologies, impacting the food business, have been encountered and it has been decided to include them into the framework to provide a more complete picture of the complexities and challenges of the food sector and to study potential future interactions and integrations among smart solutions and other used technologies.

\section{THE AGRO-FOOD SECTOR}

Before framing the food and technology value chain, it is important understanding main characteristics of the agro-food business in its-self. The agro-food sector, in fact, is complex as few other sectors are, with its diversity of products, the deterioration of fresh products within a short time, the dependency of agricultural production on weather conditions as well as on the control of diseases or pests, the limitations in the evaluation of quality characteristics at the final customer, the consumer, the relevance of commodity products, the distances between areas of production and areas of consumption, the dependency on cultural backgrounds in production and consumption, the dominance of SMEs, the volatility of markets and prices, and many other issues of similar relevance [1]. The food sector supply-chain spams from agriculture to food industry, logistics and distribution, restoration, final consumer and waste processing (fig. 1).

Each of these areas has its own characteristics and different needs and the same technology can address disparate problems: from food traceability for fraud and authenticity awareness to 
supply chain monitoring, and from food factory design for food safety to waste mechanism. Moreover, collaboration inside the supply-chain can be vertical, meaning related to a single farm production (e.g. fruit (apples, etc.), diary (milk, etc.), meat and fish (pork, tuna, etc.)) and horizontal, for instance producers associations (e.g. Parmigiano cheese consortium) and supermarket groups. Both vertical and horizontal aggregations cooperate together dynamically to stay competitive on the market and to assure quality and safety of the food products [1].

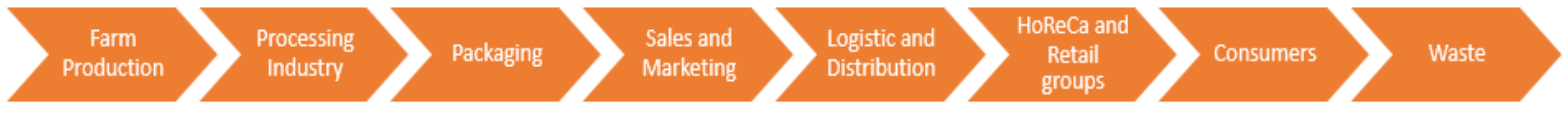

Fig. 1. Food sector supply-chain

Inside this complex picture a wide set of technologies are used to optimize processes, solve problems, enable efficient collaboration between different actors of the chain and envisage new business opportunities.

Fig. 2 summarizes the food and technology extended value chain.

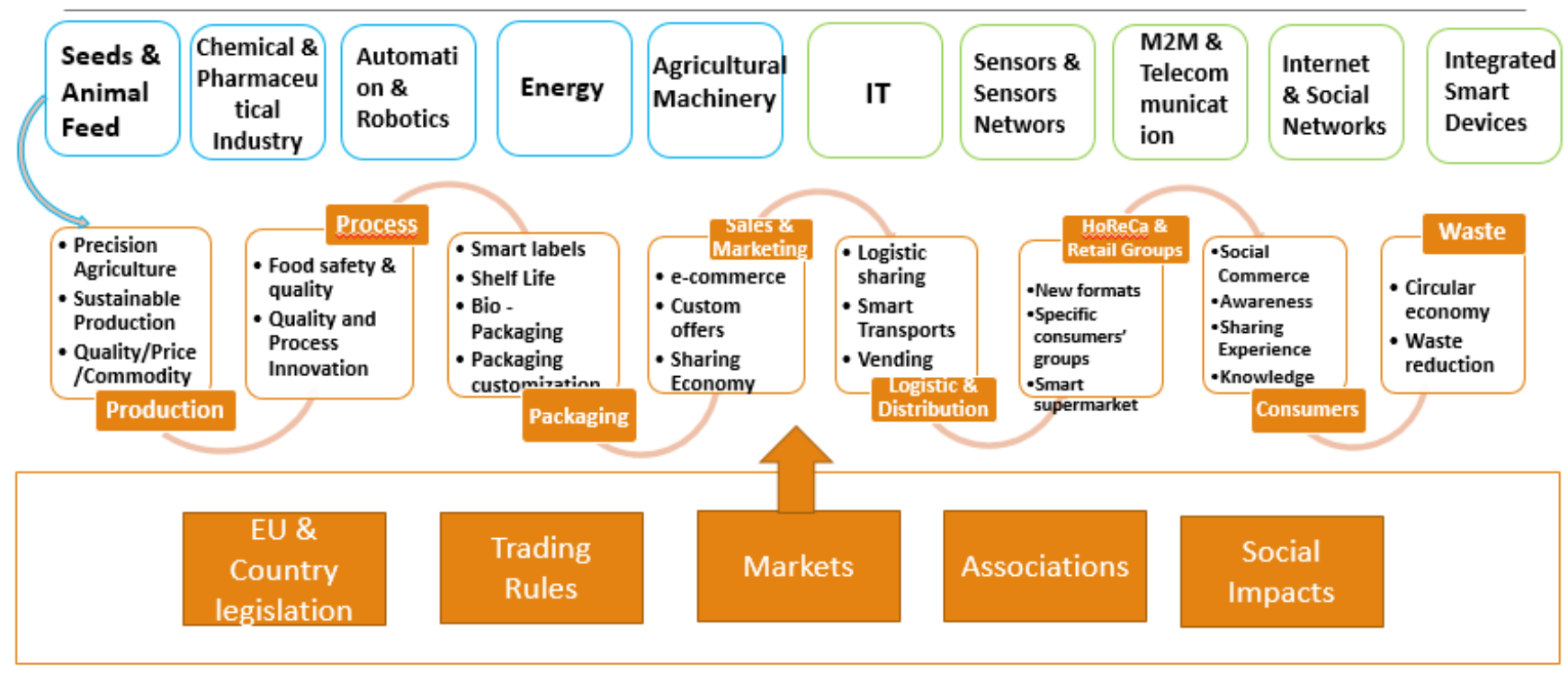

Fig. 2. Food and technology extended value chain

The proposed frame presents the food supply-chain and its main challenges solved by technological solutions, it lists the main technological actors in the value chain highlighting ICT and IoT technologies (blue boxes) from other engineering, chemical and bio solutions (green boxes) and it points out the strong influence of regulations, policies, commercial interactions and social impacts on the sector. The first part (Chapter IV) of this study briefly describes the influence and usage of technology inside the different sectors. The second section (Chapter V) underlines how the ICT and IoT can provide added value to the whole food supply-chain through traceability, virtualization and business integration adoption. A common point of the two sections is the communication capability of the presented technologies and solutions as enabling factor of their usage. Even if not treated in details here, there are several communication options available to make objects smart and it worth at least mentioning: radio-frequency and wireless communication, consolidated GSM and new low power sensors networks, like LORA and Sigfox, and M2M communication protocols. Interoperability of the different solutions is, of course, one of the main challenge for networks of diverse objects. Moreover, the development of reconfigurable embedded telecommunication SIMs is another step towards standardization, since it allows the same sensor to register to different network operators in the world without changing its internal SIM, permitting manufactures to develop just one single universal sensor-based solution, for their connected machines, to be used around the world and remotely programmed [10].

\section{THE TECHNOLOGY INSIDE THE SINGLE DEPARTMENTS OF THE FOOD SUPPLY-CHAIN}

\section{Farm Production}

Farm production includes agriculture, stock breeding and fishing. Its main challenges are optimization of production and climate changes issues, sustainability, quality and authenticity of products and commodity market price. The technological approach considers scientific chemical, biological and OGM studies (forbidden in EU with the 2001/18/CE regulation) on seeds and animal feeding food, and the adoption of Precision Agriculture, also known as "smart farming" [10]. Precision agriculture includes electronic sophisticated (GPS, telematics, Geo-fencing) equipped tractors able: to communicate and being monitored and controlled remotely, to recognize the different soils and to process and seed them appropriately, to spread fertilizers and pesticides in the most precise and fast way, reducing their quantity on plants and saving farmers money. Automated smart vehicles and robots (even collaborative ones with humans) are used for harvesting fruits (e.g. 
www.agrobot.com) and vegetables and to transplanting crops from nursery to field (e.g. www.planttape.com).

Although some commercial models, like Agrobot, and adoption in dedicated environments (usually indoor farming and greenhouses), those machines are usually at prototyping stage (e.g. http://www.sweeper-robot.eu), because of their limited performances. On average, localization success is $85 \%$, detachment success is $75 \%$, harvest success is $66 \%$, fruit damage is $5 \%$, peduncle damage is $45 \%$, and cycle time is $33 \mathrm{~s}$ [11]. Drones, with video-cameras, and Geo-localization systems, like GPS and satellite technologies, help in scanning and monitoring fields. Moreover the combination with multispectral cameras and big data analytics, to calculate and compare plants health tracking indexes, according to mathematical models, assists in managing water and pesticide distribution and in checking crops status and production maturity [24]. Parrot Sensefly ${ }^{1}$ drones are a commercial example of them. Smart sensors systems, connected to cloud computing solutions, are used to monitor ground humidity, for controlled and rationed fields irrigation, and local weather conditions to forecast climate issues, insects' attacks, maturity stages and so on, in order to improve production quality and reducing pesticides usage. Also livestock's farmers adopt drones and animals and grass fields monitoring sensors systems, to better control animal localization, health and milk production. Cattle monitoring also includes wearable devices [2]. According to a 2015 research in the Netherlands almost two fifths of the farms surveyed have adopted some sensor-based farm monitoring [3]. Sensor data are also the initial starting point of the tracing systems of the food product life-cycle, which is discussed in chapter $\mathrm{V}$, since it involves the whole supply and value chain and can lead to future innovation and business evolution of the sector. Historical sensors data can also be used in ICT Management and Decision Support Systems, processing and analyzing big data, to assist the farmer in farm management, field activities organization and planning (soil preparation for seeding, harvesting time, etc.) and financial analysis. A recent example of this in the Italian market are Horta systems: vite.net [4], grano.net. Other technological tools available in agriculture and breeding activities are portable spectrometers able to measure crop maturity and level of specific molecules, responsible of high quality of the food and other portable analysis instruments able to perform chemical analysis directly on the fields, for instance for milk quality, to decide the correct market for the product (diary vs beverage industry). For wine grape phenolic maturity monitoring, for instance, the screening of fruit chlorophyll fluorescence to measure both flavonol and anthocyanin contents of intact berry skin is a rapid and non-destructive method that can be used in addition to color analysis. It provides a quantitative measure for the grape quality and can help farmers to separate their production on quality basis, to understand the best level quality productive areas of their fields and taking corrective actions to improve it in the different zones. Commercial portable spectrometers are already available: Dualex FLAV ${ }^{\mathrm{TM}}$ and Dualex ANTH ${ }^{\mathrm{TM}}$ (and a prototype, Multiplex) [5]. In addition to precision agriculture, two new production techniques are getting very popular and can solve production problems in urban contexts and against the depletion of sea resources. They are hydroponic, which allows vertical farms fed with LED light and requiring a very low quantitative of water, and aquaculture, a recirculating system, where crops and fishes feed each other through their emitted substances in the sharing water. Both of them are very sensitive to environmental conditions, so they need proper monitoring systems, made of different sensors [12], [13].

\section{Food Processing Industry}

Agricultural, animal and fishing products are the input sources of the processing industry, which is part of the manufacturing sector. Food processing is affected either in a minimal or maximal capacity. Minimally processed food products are very similar to their unprocessed food. In these cases, processing is conducted to reduce pathogenic contaminants or to prolong shelf-life, better explored in the packaging section. Maximally processed food products, instead, differ significantly from their raw materials and they pass through several machines, mechanisms and processes [14]. Considering this complexity and variety, this paper only concentrates on some specific food challenges, excluding the typical industry 4.0 topics, like robotics. Food safety, quality and innovation of products and processes are the main issues to be address here. Food safety definition by Codex Alimentarius Commission (CAC) in 1997 is: "Food safety is the assurance that food will not cause harm to the consumer when it is prepared and/or eaten according to its intended use." Risk management and safety assurance management systems (HACCP) are in place in industry, mostly at paper level, to guarantee safety. Moreover, quality certification systems are adopted, like BRC, ISO standards. From technology point of view, the food safety in the factory can be guarantee through an integrated monitoring system of sensors along the production line and ICT receipts versioning control systems. Some of the data collected can be: monitoring of temperature and time during the different processing operations; $\mathrm{pH}$ and conductivity during cleaning in place (CIP) operations, detection of foreign bodies (e.g. X-ray detectors), chemical contaminations and microbial contaminants; monitoring of allergens; measurement of food quality characteristics, like texture, color, flavors (e.g. electronic nose and tongue); monitoring of micronutrients, moisture content, fat content and other food components [14]. Moreover, barcodes and RFID can be used along the production lines to trace the different production phases and they can also be integrated with other tags along the remaining supply-chain, as it will be explained in chapter V. Other technological trends are nanotechnologies, which are better explained in the packaging section, and food 3D printers. Even if at early research stages Additive Manufacturing (AM) in food already provides different $3 \mathrm{D}$ printing techniques: direct printing through extrusion printers, direct printing through binder jetting and mold printing. So far the available ingredients are limited to some inorganic products, but some interesting experiments have been already conducted worldwide. In Italy Barilla organized a 3D printing context in 2015, where three completely new formats, almost impossible to create without the AM techniques, were printed. The Spanish Natural

${ }^{1}$ https://www.sensefly.com/applications/agriculture.html 
Machines is developing Foodini, a compact size, multiingredients $3 \mathrm{D}$ printer, able to print pizza, ravioli and hamburgers at raw status [15].

\section{Packaging}

Main trends here are smart packaging and smart labels used for products primary shelf life extension and product monitoring status, sustainable and bio packaging creation, and products customization formats. Regarding primary shelf life, both process and packaging industries are concerned, since main shelf life is set initially during the food processing, but it can be also monitored and extended through the appropriate package choice. Among the different ways to enlarge the primary product shelf life, nanotechnologies are a trend in packaging. The nanosensors may be either located inside the food product or on the surface. Nanosensors can be biological assays, probes, or nanostructures coated with recognition particles. They can recognize pathogens and organic particles, they can measure $\mathrm{pH}$ and detect hydrogen protons and organic molecules, such as proteins. Integrated into smart packaging solutions nanosensors can be useful to better preserve the food, extending its shelf life, and to monitor the status of the food product. Nanosensors can also be used for creating smart labels [14]. The labels have reactive layers with nanoparticles or nanoassays to gather environmental information within the packaging and they can send the measured data through wireless protocols. The cheapest and the most explored data transfer option is via radio frequency identification tags (RFID). At the moment, the smallest micro RFID tags are approximately $50 \times 50 \mu \mathrm{m}$ [6]. RFIDs are also used at macroscale level to provide smart labels together with barcodes and QRcodes, also called smart tags. They can be scanned though smartphone and tablets by food operators and consumers to get information about the product or other contents provided. It is important to notice labels are strictly regulated by EU through 1169/2011 regulation, which defines labels and character size and compulsory content about food characteristics, composition and properties to be provided to the customers. Nanomaterial contained in food, must be declared in the label, for instance, as so allergens and by 2017 nutritional information will be mandatory as well.

\section{Sales \& Marketing}

Main technology used in this sector is related to the interface with customers. It includes e-commerce web sites, Social media for products and initiatives advertisements, APPs for receipts and other engaging customers contents, and smart tag, mainly QRcodes on labels and recently NFC tags, for extended products and company services information. During EXPO 2015 in Milan, the CNR FINe (the Food In the Net) observatory presented the results of the presence of agro-food Italian companies in the web, which is only of $7,1 \%$. On a total of 1.400 .000 agro-food companies present in the .it domain's register, only $100.000(7,1 \%)$ have a web site: $38,52 \%$ agriculture, $10,94 \%$ wine, $7 \%$ pasta, $5,13 \%$ breeding, $2,76 \%$ extra virgin olive oil and the remaining are related to other connected activities, like farm tourism [16]. Regarding social media, the only collected info are about the wine sector, where among the 25 main Italian producers, $68 \%(=17)$ is present on Facebook, 48\% (=12) on Twitter and 12\% (=3) publishes videos on YouTube [17]. On the other end the "Multichannel" and "eCommerce BtoC" Observatories of the Politecnico di Milano reported in 2015 the strong increase of smartphones internet access $(+20 \%$ users from 2014) with $65 \%$ of smartphone usage time for surfing and a $+20 \%$ of e-commerce purchasing. From customer point of view: $+4 \%$ increase of social shoppers $(68 \%$ over 45$)$ and $+29 \%$ increase of hyper reloaded $(+63 \%$ 20-44 years old) has been registered in one year. Multichannel shopping goods percentages at large retails groups are: $44 \%$ functional food, $32 \%$ pet food, $24 \%$ hot beverages, $17 \%$ baby food, $15 \%$ food [18]. e-Commerce services through APP are also upcoming businesses (e.g. www.vivino.com), sometimes linked with QR code scanning trigger (see QRcode stores in the HoReCa section). The usage of QRcodes and NFC tags, anyway, is still under development and companies are experimenting solutions. Not clear statistics are available about their usage and success so far.

\section{Logistic \& Distribution}

Main challenges of logistic and distributions are not just time delivery and product tracking through RFID, but also optimal transport conditions to preserve food product quality, characteristics and shelf life overall in the cold chain service. Sensors measuring temperature, humidity, levels of different gases inside the containers at vehicle, pallet and eventually single product granularity send the collected data through wireless gateways to warehouses management systems to allow remote monitoring and alert messages in case of problems. The product quality that is lost by a deviation from the recommended transport conditions depends on its duration and magnitude as well as the individual sensitivity of the product type. Sensors data can effectively being combined with advanced mathematical algorithms to recalculate food product shelf life, when a transportation problem has been registered by the monitoring system [7]. A niche sector of food distribution industry is the Vending sector, which is also categorized under the retail industry. Vending sector, where Italy is a worldwide recognized leader, is one of the most active in the IoT adoption. In the 2015, during TUTTOFOOD commercial fair, a dedicated section for Vending Industry (Venditalia 2015 Special Edition) presented 11 high technology projects, where vending machines become smart objects in itself able to prepare customized drinks and heating food on the go and to interact with customers through touchscreens and APPs on their smartphones. In this way IoT solutions help the vendors also to comply with UE regulation 1169/2011 offering products information about ingredients and allergens to the customer before the selling [19]. The trend of customized products in vending machines could perhaps lead in future to the integration with 3D food printers. AM of food is, in fact, a nascent field with great potential but yet limited application, in search of utility. The key motivators for 3D printing food are customization, on-demand production, and geometric complexity [8]. At the 2014 South by Southwest festival, an Oreo vending-machine prototype fashioned custom cookies on the spot based on Twitter trends [15].

\section{HoReCa \& Retails Groups}

Technology offers several business opportunities to this segment starting from smart supermarkets, with collaborative 
robots, sensors scans, RFID, e-beacons and QRcode to engage customers, pass through virtual groceries enabled by QRcodes, until new startups in the food services. An example of smart supermarket was presented at EXPO 2015 by $\mathrm{COOP}^{2}$ Regarding the QRcode stores, Tesco, in US, launched the Virtual Store in 2009 and is now opening new stores worldwide. In Europe Jetshop, in Sweden, offers a QRcode supermarket and Ocado in UK a QR Code virtual window [20]. In Italy the Gruppo Vegè retail chain in 2015 started using e-beacon technology for proximity marketing in one of its stores ${ }^{3}$. Another trend are the several new born digital food services startups. Wineamore provides a B2B wine menu to restaurants and wine producers ${ }^{4}$. OutdoorSafeFood ${ }^{5}$ delivers to bar and restaurants ready to eat meals for celiac people and other food sensitive persons and several other internet food companies are present in the B2C market, like Cortilia ${ }^{6}$, Supermercato $24^{7}$, Gnammo $^{8}$, Mamau 9 . All of these startups address niche and targeted consumer segments and tastes, not always highly considered by traditional food groceries.

\section{Consumers}

As described in the previous sections, consumers trends about smart technology, food consumption and purchasing behavior are changing quickly during last 5 years. Smartphone diffusion, Social Networks and public advisory sharing web sites, like TripAdvisor, APPs availability and smart tags (QRcodes and NFC) are enabling the digital shift overall in millennials and under 45. Even socializing is now a digital sharing experience. Food companies are trying to engage customers through technology, not just at the selling time, but also with open innovation services, where clients can provide direct feedback to producers about the content, the taste, the format and other characteristic of the products, which are then analyzed to create more customized offers. Barilla, for instance, shares with its customers the website: www.nelmulinochevorrei.it. On the other end, social trends towards km0 production, "Made In Italy", Biological products, increased people health issues related to food, like allergic reactions, and fear of food infections and alerts strength the consumers to request food companies to provide more information, awareness, and transparency about food origin and quality [21]. This leads to traceability along the whole supplychain, which will be described in chapter V.

\section{Waste}

According to Politecnico di Milano waste engraves on consumers behavior for $47 \%$ and on the rest of the food supply chain for 52\% [23]. Adoption of smart technology in food waste reduction is limited to RFIDs systems to monitor and recover the waste of product along the production lines. Supermarkets and retails are experimenting, through startup providers web sites services and APPs, solutions to offer discounts to consumers for products close to shelf life deadline (e.g. www.myfoody.it, www.lastminutesottocasa.it) and to charity organization feeding homeless people (e.g. www.breading.it).

\footnotetext{
2 https://www.youtube.com/watch?v=nJVoYsBym $88 \&$ feature=player_embedded

3 http://www.gruppovege.it/approfondisci?id=8

${ }^{4}$ http://www.wineamore.com/index.php?lang=it

5 http://www.outdoorssafefood.it
}

This last case in Italy still needs legislation improvements, due to safety restrictions for food donations and related financial issues [23].

\section{TRACEABILITY AND SUPPLY-CHAIN MANAGEMENT WITH INTERNET OF THINGS PERSPECTIVE}

Food traceability has been introduced in Europe with $\mathrm{n}$. 178/2002 EU regulation, effective in Italy from 2005 on. It applies to all food products, animals and seeds and it is defined as "... the ability to track and/or trace product flow in a production and distribution chain ..." [1]. It is usually managed through barcodes reporting the few requested information about food and animal origin's farm. The emerging capabilities of smart technologies are now able to trace the food production along the whole supply-chain not just in terms of item identification and site of origin and processing factories, but also along the whole product lifecycle for quality, fraud, adulteration and authentication requirements, for impact on people health and for marketing and business purposes. This implies the track of the food item, and other product characteristics, like chemical and biological ones, manipulation processes passed through, storage and transport conditions. Starting from farms, geo-localization systems, and networked, wireless and radio communicating sensors provide data about the raw products and animals. In addition DNA sequencing and barcoding (in order to retrieve data electronically) can trace cultivar and species varieties of plants, animals and fish. This can guarantee the true site of origin of the raw material and authenticity of the plant, animal, fish type and ingredient, when the product travels along the supply-chain. Moving to processing industry, RFID and barcode can identify the raw products along the whole processing chain until the packaging stage. Regarding the origin's authenticity and specific characteristics of the raw ingredients, minimum processed food, like fish fillets and meat slices, can be identified through DNA barcodes. Moreover, thanks to development of handheld and inline analytical equipment, onsite non-destructive measurements can carry out on processed food. These are mainly portable spectrometers, lab-on-a-chip and, possibly in future, smartphone (spectrometer) detectors. Lab-on-a-chip are very sensitive, specific, low cost, energy efficient, robust and fast in performing analysis and they can be connected to computers to send data in real time remotely [22]. Moving to packaging phase, the already mentioned barcodes and RFIDs are used for package and logistic identification. QRcodes, NFC and nanomaterial combined RFIDs can trace food origin, properties and characteristics to be read by the final consumers during and after the purchasing to get product awareness. Packaged food is then stocked in warehouses and then transported to the selling market. Again RFID is used in the warehouse management, while, during transport, environmental conditions can be monitored through different sensors at truck, pallet and product level and shelf life can eventually be recalculated in case of problems through specific algorithms. All these parameters can be saved to cloud IT systems and read with smartphones and

\footnotetext{
${ }^{6}$ www.Cortilia.it

7 www.supermercato24.it

${ }^{8} \mathrm{https://gnammo.com/}$

9 http://mamau.it/
} 
tablet and even provided to business clients for a better management of the market/supermarket warehouse, with a FEFO (First-Expire, First-Out) logic and to consumers through the scan of QRcodes and NFC tags. Examples of complete tracking from farm to fork can be find in the EU FP7 ICT programme $^{10}$. In Italy the Safety4Food ${ }^{11}$ and QRcode Campania ${ }^{12}$ projects are still on going. Sharing the food product tracking information about the location of the items and their health status has lead to supply-management integrated systems, where the main business actors of the supply-chain collaborate, helped by ICT and sensors systems, to reduce time and process inefficiencies along the chain and then saving money. The evolution of integrated supply-chain management is now evolving towards IoT cloud distributed solutions and big data analysis of the traced information. Single connected objects (physical layer) can communicate their information to an ICT system (data exchange layer), which creates a virtual representation of each of them (information integration layer). This object avatar is continually updated by its physical counterpart and it is shared in a common supply-chain cloud system, where their data are integrated to provide specific services to the different stakeholders of the supply-chain (application service layer). Services can be information handling, problem notification and decision making, where objects are able to make relevant decisions by themselves. In this way the management of part or entire supply-chain processes can be virtualized and automatized, implementing the Internet of Things paradigm [9].

\section{CONCLUSION}

The development of smart technologies together with other manufacturing, engineering and fingerprinting chemical solutions is changing the food sector in each part of its supplychain, promoting more a more system and business integration towards the IoT paradigm adoption. Some commercial technologies are already available and early adopters companies are experimenting new business opportunities to stay competitive in the global market. Possible future applications have been suggested in the text of this paper. Still some problems about digital divide, low telecommunication coverage in the rural areas, systems interoperability and standardization communication systems need to be solved to improve the adoption of the presented technologies. Also big data collection, filtering and interpretation are a challenge in the IoT development and diffusion. Moreover, legislation constraints and consumer opinions, e.g. about nanomaterials, and behaviors can influence their large adoption.

\section{REFERENCES}

[1] R. J. Lehmann, R. Reiche, and G. Schiefer, "Future internet and the agri-food sector: State-of-the-art in literature and research," Comput. Electron. Agric., vol. 89, pp. 158-174, 2012.

[2] D. Smith, S. Lyle, A. Berry, and N. Manning, "Internet of Animal Health Things (IoAHT) Opportunities and Challenges," 2015.

[3] K. Bhargava, S. Ivanov, and W. Donnelly, "Internet of Nano Things for Dairy Farming," Proc. Second Annu. Int. Conf. Nanoscale Comput. Commun. - NANOCOM' 15, pp. 1-2, 2015.
[4] V. Rossi, F. Salinari, S. Poni, T. Caffi, and T. Bettati, "Addressing the implementation problem in agricultural decision support systems: the example of vite.net ${ }^{\circledR}, "$ Comput. Electron. Agric., vol. 100, pp. 88-99, Jan. 2014.

[5] Z. G. Cerovic, N. Moise, G. Agati, G. Latouche, N. Ben Ghozlen, and S. Meyer, "New portable optical sensors for the assessment of winegrape phenolic maturity based on berry fluorescence," J. Food Compos. Anal., vol. 21, no. 8, pp. 650-654, Dec. 2008.

[6] D. Ileš and G. Martinović, "Review of Potential Use, Bene $\square$ ts and Risks of Nanosensors and Nanotechnologies in Food," vol. 53, no. 2, pp. 127-136, 2011.

[7] R. Jedermann and W. Lang, "The benefits of embedded intelligence - Tasks and applications for ubiquitous computing in logistics," Lect. Notes Comput. Sci. (including Subser. Lect. Notes Artif. Intell. Lect. Notes Bioinformatics), vol. 4952 LNCS, pp. 105-122, 2008.

[8] J. I. Lipton, M. Cutler, F. Nigl, D. Cohen, and H. Lipson, "Additive manufacturing for the food industry," Trends Food Sci. Technol., vol. 43, no. 1, pp. 114-123, May 2015.

[9] C. N. Verdouw, J. Wolfert, A. J. M. Beulens, and A. Rialland, "Virtualization of food supply chains with the internet of things," $J$. Food Eng., vol. 176, pp. 128-136, 2015.

[10] "Towards Smart Farming, Agriculture embracing the IoT vision", Beecham Research, 2015

[11] C. W. Bac, E. J. van Henten, J. Hemming, Y. Edan, "Harvesting Robots for High-value Crops: State-of-the-art Review and Challenges Ahead", Journal of Field Robotics, vol. 31, pp. 888-911, 2014

[12] Y. Zhang, J. Hua, Y. B. Wang, "Application Effect of Aquaculture IOT System", Applied Mechanics and Materials, vols. 303-306, pp. 1395-1401, 2013

[13] R. E. N. Fang, "Talking about the Application of On-line Water Quality Monitoring System in Aquaculture Based on IOT (Internet of Tings)", Shanxi Science and Technology, vol. 4 pp. 068, 2014.

[14] M. Nitaigour, K. Kiseon, "The Role of Information Technology Developments in Food Supply Chain Integration and Monitoring", Innovation and Future Trends in Food Manufacturing and Supply Chain Technologies, vol. 21, pp. 21-37, 2015.

[15] "3D opportunity serves it up: Additive manufacturing and food", Deloitte University press, 2015

[16] "The Food in the Net observatory": i dati sull'agroalimentare in Rete, http://www.nic.it/news/\%E2\%80\%9C-food-net-observatory-datisull\%E2\%80\%99agroalimentare-rete, December 2015

[17] "Il gusto digitale del vino italiano", FleishmanHillard Italia research, http://fleishman.it/2015/05/il-gusto-digitale-del-vino-italiano-

fleishmanhillard-italia-presenta-la-classifica-della-presenza-onlinedelle-prime-25-aziende-vinicole-italiane-per-fatturato/, 2015

[18] "Multicanalità: qual è la novità?", research of Osservatorio Multicanalità of Politecnico di Milano, www.multicanalità.it, 2015

[19] "Vending è Vita", ed. Venditalia servizi, $\frac{\text { www.venditalia.com }}{2015}, 2015$ Store examples",
[20] "Top 10 QR Code http://www.shop2mobi.com/blog/virtual-qr-code-store-examples/, last access April 2016

[21] G. Nocella, D. Romano, and G. Stefani, "Consumers' attitudes,trust and willingness to pay for food information," International Journal of Consumer Studies, vol. 38, no. 2, pp. 153-165, 2014

[22] A. M. Pustjens, Y. Weesepoel, S. M. van Ruth, "Food Fraud and Authenticity: Emerging Issues and Future Trends" Innovation and Future Trends in Food Manufacturing and Supply Chain Technologies vol. 1, pp. 3-20, 2015

[23] "Surplus Food Management Against Food Waste. Il recupero delle eccedenze alimentari. Dalle parole ai fatti", a Politecnico di Milano research, http://www.expo2015.org, 2012

[24] "How To Select an Agriculture Drone: An In-Depth Buyer's Guide", http://bestdroneforthejob.com/drone-buying-guides/ agriculturedrone-buyers-guide/, May 2016

\footnotetext{
$12 \mathrm{http}: / /$ www.qrcodecampania.it/
} 